Article

\title{
Genetic Dissection of Disease Resistance to the Blue Mold Pathogen, Peronospora tabacina, in Tobacco
}

\author{
Xia Wu ${ }^{1,2}$, Dandan Li ${ }^{1}$, Yinguang Bao ${ }^{1,2}$, David Zaitlin ${ }^{3}$, Robert Miller ${ }^{1}$ and \\ Shengming Yang 1 ,*
}

1 Department of Plant \& Soil Sciences, University of Kentucky, Lexington, KY 40546, USA;

E-Mails: xwu225@uky.edu (X.W.); dli2@uky.edu (D.L.); ygbao@ sdau.edu.cn (Y.B.); rdmiller@uky.edu (R.M.)

2 Department of Plant Genetics and Breeding, Shandong Agricultural University, Shandong 271018, China

3 Kentucky Tobacco Research \& Development Center, University of Kentucky, Lexington, KY 40546, USA; E-Mail: david.zaitlin@uky.edu

* Author to whom correspondence should be addressed; E-Mail: syang2@uky.edu; Tel.: +1-859-257-3586; Fax: +1-859-323-1077.

Academic Editor: Diego Rubiales

Received: 15 July 2015 / Accepted: 23 November 2015 / Published: 27 November 2015

\begin{abstract}
Tobacco blue mold, caused by the obligately biotrophic oomycete pathogen Peronospora tabacina D.B. Adam, is a major foliar disease that results in significant losses in tobacco-growing areas. Natural resistance to $P$. tabacina has not been identified in any variety of common tobacco. Complete resistance, conferred by $R B M 1$, was found in $N$. debneyi and was transferred into cultivated tobacco by crossing. In the present study, we characterized the $R B M 1$-mediated resistance to blue mold in tobacco and show that the hypersensitive response (HR) plays an important role in the host defense reactions. Genetic mapping indicated that the disease resistance gene locus resides on chromosome 7 . The genetic markers linked to this gene and the genetic map we generated will not only benefit tobacco breeders for variety improvement but will also facilitate the positional cloning of $R B M 1$ for biologists.
\end{abstract}

Keywords: tobacco; blue mold; disease resistance; genetic marker 


\section{Introduction}

Common tobacco (Nicotiana tabacum L.) is one of the most important non-food crops worldwide, and is also a model plant for biological research [1,2]. Considerable interests have been focused on the molecular mechanisms underlying disease resistance to numerous pathogenic microbes in tobacco $[3,4]$. Several species of oomycetes, also known as water molds, are among the most devastating plant pathogens that cause notable diseases such as late blight of potato, downy mildew of grape vine, and root and stem rot of soybean. Tobacco blue mold, caused by the obligately biotrophic oomycete pathogen Peronospora tabacina D.B. Adam (syn. P. hyoscyami de Bary), is a major foliar disease that causes significant crop losses in tobacco-growing areas around the world. Annual losses exceeding \$200 million due to blue mold epidemics have been reported in the United States and Canada [5,6].

Chemical treatments have been effective in controlling the spread of blue mold disease but given the economic and environmental costs of fungicide application, harnessing host resistance is the most sustainable strategy for reducing potential crop losses from blue mold. Natural genetic variation in host-pathogen interactions is key to the development of disease-resistant cultivars. Unfortunately, natural resistance to $P$. tabacina is very low in $N$. tabacum, and most commercial varieties are highly susceptible to blue mold disease [7]. A high level of functional resistance to $P$. tabacina infection was identified in both $N$. debneyi and $N$. goodspeedii and was transferred into cultivated tobacco by crossing [8-11]. Resistant tobacco varieties were first released beginning in the 1960s. However, the genes identified in the undomesticated species appear to confer only partial resistance to blue mold infection when incorporated into cultivated tobacco through interspecific hybridizations $[8,10,12]$. A possible reason for the weakened immunity is that the expression levels of major genes from these undomesticated species are down-regulated by modifier genes in the tobacco genome [7,13]. Alternatively, genetic resistance to blue mold in $N$. debeyi could be determined by multiple factors, but not all of these genes were transferred to tobacco successfully. Nevertheless, both explanations are only speculative at present. Therefore, cloning and characterization of the Nicotiana resistance genes directed against blue mold will not only further our understanding of host resistance to oomycete pathogens but also offer new insights into the optimization of genetic resistance to this destructive disease in tobacco.

Molecular markers closely linked to the blue mold resistance locus ( $R B M 1$ hereafter) derived from $N$. debneyi have been developed and used for marker-assisted selection [9,14]. Utilization of these markers greatly facilitates tobacco breeding for blue mold resistance. Host responses to $P$. tabacina are complex and unpredictable under field conditions because multiple factors including plant age, physiological status, and environmental conditions can affect plant reactions to pathogen infection. Consequently, selection solely based on disease phenotype can be misleading. Three sequence characterized amplified region (SCAR) markers, two of which were converted from flanking random amplified polymorphic DNA (RAPD) markers [9] and one that was derived from an amplified fragment length polymorphism (AFLP) marker [14], have become valuable assets to breeding programs worldwide for the improvement of blue mold resistance in tobacco. However, these SCAR markers are dominant, precluding differentiation of plants that are homozygous from those that are heterozygous at the resistance locus, and their genetic locations are unknown. In this study, we conducted genetic mapping of $R B M 1$ and characterized genetic resistance to $P$. tabacina, providing a robust foundation for map-based cloning of $R B M 1$ and for engineering $R B M 1$-mediated resistance. 


\section{Results}

\subsection{Disease Reaction Assay and Segregation Analysis}

Typical symptoms were clearly observed on leaves of TKF (Tennessee Kentucky fertile) 2002 plants six days after spray-inoculation with the pathogen (Supplementary Materials Figure S1). The diseased leaves became spotted with grey lesions that subsequently produced areas of abundant downy sporulation on the lower surface, while leaves of the resistant parent TKF 4321 remained healthy at the same time point (Supplementary Materials Figure S1). Histological analyses were performed to monitor the course of tissue colonization by $P$. tabacina. Inoculated leaves were cleared, and pathogen structures were detected by lactophenol-trypan blue staining (Figure 1). No significant differences were noted between resistant and susceptible lines during the pre-penetration events. Spores germinated on the leaf surface and formed appressoria between 1 and $3 \mathrm{~h}$ after inoculation (hpi). Following penetration, pathogen colonization proceeded rapidly in susceptible TKF 2002 cells at 48 hpi, but no colonization was observed during this time in cells of the resistant line (Figure 1A,B). At 120 hpi, the pathogen produced lemon-shaped sporangia (spores) on tree-like branched structures (sporangiophores) that emerged from the leaf stomata in TKF 2002 (Figure 1H). In contrast, pathogen development in TKF 4321 was very restricted. By 72 hpi, only a few hyphae were observed in TKF 4321 leaves (Figure 1C). Although more hyphae were detected at 72 and 96 hpi, sporangiophores were never observed in TKF 4321 leaves. Even if sporangiophores were produced in TKF 4321, they would be very rare and difficult to detect. To test whether the hypersensitive response (HR) was involved in host defense, we inoculated tobacco by injecting $P$. tabacina into the leaves. HR-induced chlorosis was observed at the inoculation sites in TKF 4321, and it limited further development and spread of the pathogen. This was in contrast to the development of a systemic infection beyond the inoculation sites in TKF 2002 (Supplementary Materials Figure S2). Therefore, the HR appears to be an important component of RBM1-mediated disease resistance.

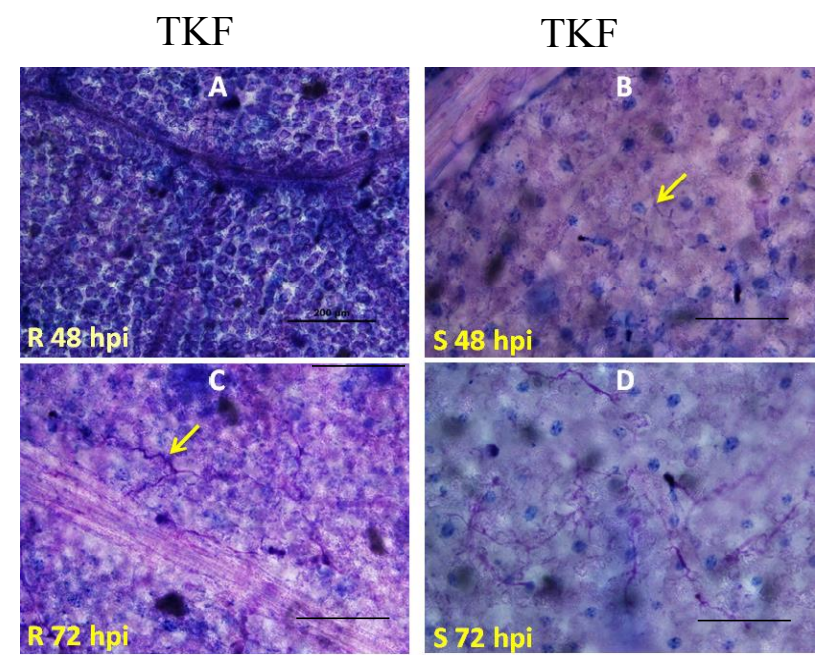

Figure 1. Cont. 


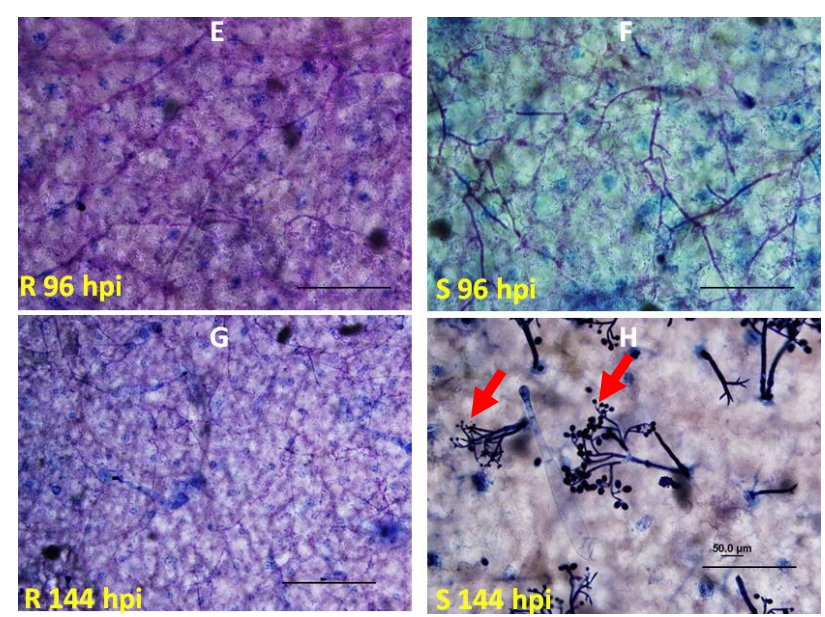

Figure 1. Histological analyses to TKF 4321 and TKF 2002 leaves inoculated with blue mold pathogen. The progress of tissue colonization by the pathogen is shown in panels $\mathrm{A}$, $\mathrm{C}, \mathrm{E}, \mathrm{G}$ in the resistant parental line TKF 4321, and in B, D, F, H for the susceptible line TKF 2002. Hyphae were stained with trypan blue and observations were performed at 48 hpi (A,B); 72 hpi (C,D), 96 hpi (E,F), and 144 hpi (G,H). The life cycle of $P$. tabacina can be quickly completed on TKF 2002 plants within six days post inoculation, but the spread of pathogen is seriously hampered on TKF 4321 plants with restricted growth of hyphae. The yellow arrows in $1 \mathrm{~B}$ and $1 \mathrm{C}$ indicate hyphae at the early stage of infection. The red arrows in $1 \mathrm{H}$ indicate sporangiophores. R, resistant; S, susceptible; hpi, hours post-inoculation.

\subsection{Genetic Mapping of RBM1}

Field experiments showed that the relative disease severity caused by $P$. tabacina infection on $\mathrm{F}_{1}$ plants was intermediate between the two parental lines, suggesting that $R B M 1$ is a semi-dominant gene (Supplementary Materials Figure S3). To avoid occasional errors in phenotyping that result from incomplete resistance expressed in the heterozygous $\mathrm{F}_{2}$ plants, we selected the susceptible individuals at the first screening and the resistant individuals at the second screening for genetic mapping. Therefore, although we inoculated a total of $862 \mathrm{~F}_{2}$ plants, only 242 resistant and 168 susceptible plants were used in the mapping of the blue mold resistance gene. The first marker linked to RBMI we identified is PT61512, which is located on linkage group (LG) 7 and is in repulsion-phase. Taking advantage of the tobacco genetic map constructed by Bindler et al. [15], we mapped RBM1 against polymorphic SSR markers on LG7 and generated a genetic map (Figure 2). As can be seen from this map, the RBM1 locus is flanked by the two dominant SCAR marker loci developed by Milla et al. [9]. After sequencing these two SCAR markers (Supplementary Materials Table S1), we performed BLAST searches, but no high-quality hit was found in any of the sequenced Nicotiana genomes. The SSR marker loci that are closely linked to RBM1, such as PT61472 and PT51405, are also in repulsion phase, and are present only in blue mold-susceptible TKF 2002. However, heterozygosity of blue mold resistance can be distinguished in a segregating population by using both the coupling SCAR markers and repulsion markers (Supplementary Materials Figure S4). 


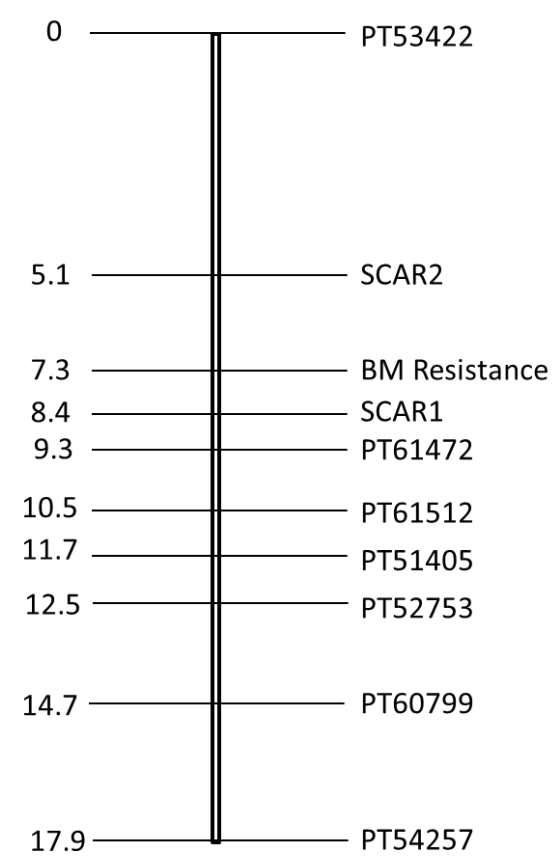

Figure 2. Genetic mapping of the RBMI locus on the linkage group 7. The genetic distance (cM) for each molecular marker is indicated on the left side of chromosome. The map is drawn to scale.

\subsection{Quantitative Analysis of Defense Responses to Blue Mold Infection}

Mounting an adequate defense response against an invading pathogen is generally dependent on the fine-tuned perception of pathogen infection and the activation of a gene expression network that results in the production of reactive oxygen species (ROS) and synthesis of pathogenesis-related (PR) proteins. To better characterize $R B M I$-mediated resistance to $P$. tabacina, we conducted real time-PCR to quantitatively analyze changes in gene expression for $P R 1$ and $P R 4$, and also for $H S R 203 J$, a molecular marker of HR cell death [16]. The expression kinetics for all three genes exhibited a similar trend. The genes were expressed at a significantly higher level in the resistant parental line, TKF 4321, than in the susceptible line TKF 2002 starting in the middle of the sampling period, although these genes were also induced gradually to a remarkable level in TKF 2002. The oxidative burst is known to be a hallmark of successful recognition of infection and activation of plant defenses [17]. To test whether ROS plays a role in tobacco resistance to blue mold, we quantified and compared $\mathrm{H}_{2} \mathrm{O}_{2}$ levels in resistant and susceptible plants. TKF 2002 and TKF 4321 had similar basal levels of $\mathrm{H}_{2} \mathrm{O}_{2}$, and pathogen infection induced a comparable increase in $\mathrm{H}_{2} \mathrm{O}_{2}$ levels for both lines at $72 \mathrm{~h}$ post inoculation. Interestingly, production of $\mathrm{H}_{2} \mathrm{O}_{2}$ in TKF 2002 appeared to reach a peak at $72 \mathrm{hpi}$, but $\mathrm{H}_{2} \mathrm{O}_{2}$ production continued to increase in TKF 4321, and the maximum level was observed at $96 \mathrm{hpi}$. Even at $120 \mathrm{hpi}$, the level of $\mathrm{H}_{2} \mathrm{O}_{2}$ in TKF 4321 remained high, in contrast with a trend of declining $\mathrm{H}_{2} \mathrm{O}_{2}$ production in TKF 2002 at the same time point. 


\section{Discussion}

Development of disease-resistant cultivars is an effective way to control diseases if sufficient genetic variation for host resistance is available. When sources of resistance are limited, breeders must turn to the secondary gene pool for species that can hybridize with the cultivated species. Molecular techniques enable the transfer of resistance genes between much more distantly related species. In the Solanaceae, several $R$ genes have been shown to confer resistance reactions to pathogens carrying the appropriate Avr (Avirulence) genes when transferred to other solanaceous species. Transferring tomato $C f-9$ to tobacco and potato, pepper $B s 2$ to tomato, tomato Pto to tobacco, and the tobacco $N$ gene to tomato, demonstrated that $A v r$-dependent $R$ protein-triggered signaling cascades are conserved in diverse species in the Solanaceae [18-21].

Given the scarcity of genetic resources for resistance to blue mold in common tobacco, breeders introgressed blue mold resistance conferred by RBMI from $N$. debneyi into tobacco to reduce the potential for losses from this disease. The two SCAR markers developed by Milla et al. [9] provided valuable tools for early selection on breeding for blue mold resistance. However, the SCAR markers are dominant, precluding differentiation of plants that are homozygous from those that are heterozygous at the resistance locus, and their locations in the tobacco genome are unknown. In the present study, genetic mapping indicates that RBMI is located on LG 7. In addition, the repulsion markers, in combination with the coupling-phase SCAR markers, make it possible to distinguish heterozygosity of blue mold resistance in a segregating population. As a result, marker-assisted selection for blue mold resistance in tobacco will be achieved with improved efficiency.

Although RBM1 contributes significantly to the control of blue mold disease, one pitfall is that RBM1-mediated immunity in tobacco is not as fully functional as it is in N. debneyi. While P. tabacina infection was highly restricted in TKF 4321, hyphae were still produced, although with a reduced occurrence (Figure 1C). Thus, while limiting the extent of pathogen spread, RBM1-mediated resistance appears to be temporally slower and of lower amplitude than the typical defense responses conferred by plant resistance $(R)$ genes such as NBS-LRR genes that encode nucleotide-binding site leucine-rich repeat proteins. $R$ gene-mediated disease resistance is often associated with the hypersensitive response (HR), which is characterized by a rapid, localized cell death that serves to suppress pathogen spread at the infection sites. Hand-inoculation of tobacco leaves confirmed that the HR plays a role in defense against $P$. tabacina infection, in agreement with the induced expression of HSR203J observed in this host-pathogen interaction (Supplementary Materials Figures S1 and S3). It has been demonstrated that the gene product of $H S R 203 J$ is a serine hydrolase with a potential role in the degradation of harmful compounds [22]. Activation of HSR203J is rapid, highly localized, and is correlated with programmed cell death in tobacco in response to various HR-inducing pathogens or elicitors [23]. Therefore, HSR203J has been used as a marker gene to identify the triggering of the HR-mediated defense response [24,25]. Activation of this gene is usually observed several hours after pathogen infection. However, transcription of HSR203J was induced at $48 \mathrm{hpi}$ and attained its highest level at $120 \mathrm{hpi}$ in TKF 4321 infected with P. tabacina (Figure 3). The molecular basis to explain why the HR is delayed or impaired is presently unknown. 


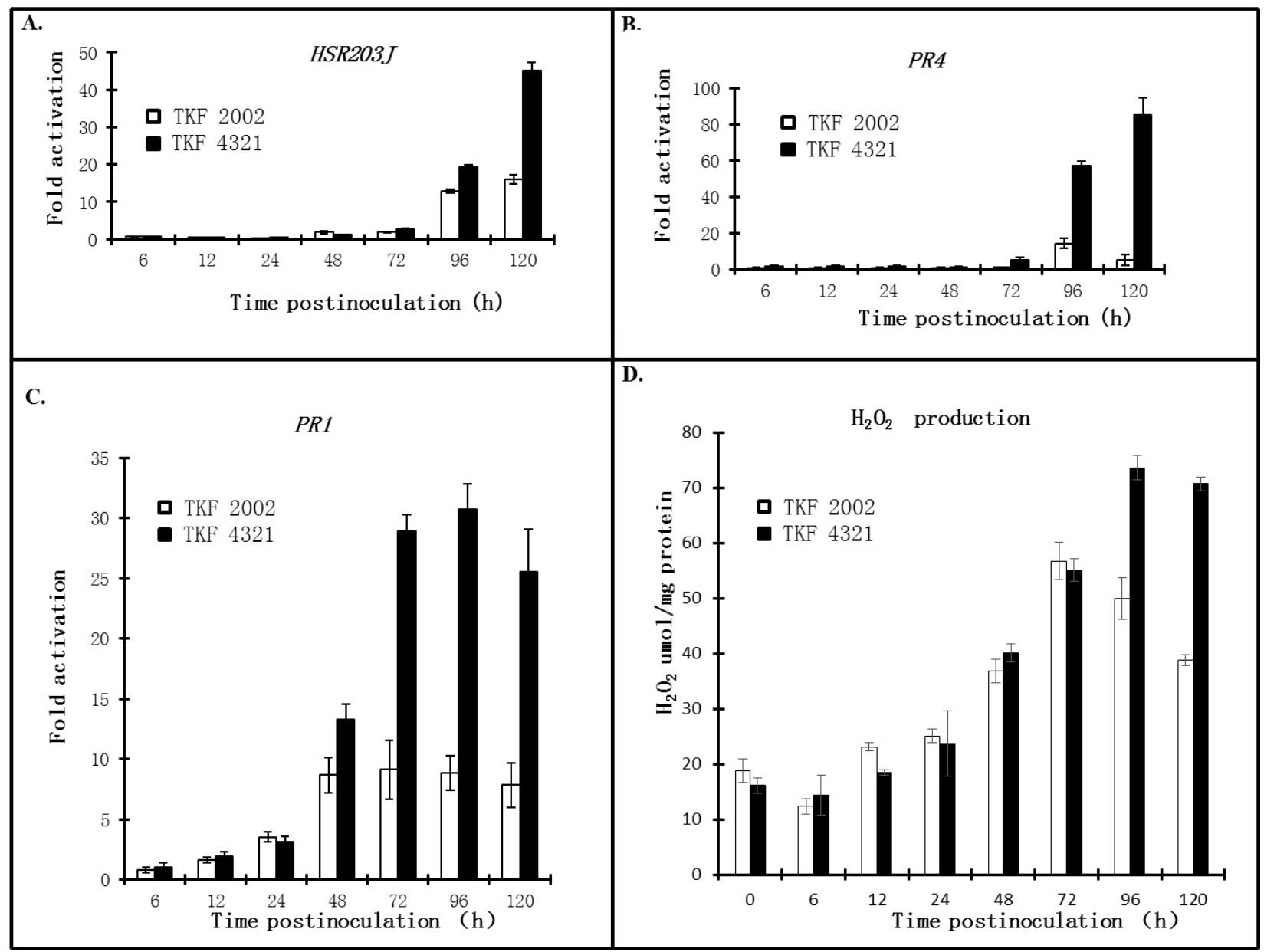

Figure 3. Real-time PCR analysis of host responses and $\mathrm{H}_{2} \mathrm{O}_{2}$ production during blue mold infection of tobacco. Expression profiles for HSR203J, PRl, and PR4 were determined at seven time points between six and 120 hpi $(\mathbf{A}-\mathbf{C})$. Quantification of endogenous $\mathrm{H}_{2} \mathrm{O}_{2}$ in tobacco leaves is shown in 3D.

The guard hypothesis may provide implications for the transfer of disease resistance. The genetic interaction between R and Avr proteins can be explained by the guard hypothesis [26]. This model seeks to explain how $\mathrm{R}$ proteins activate resistance by interacting with another plant protein (a guardee) that is targeted and modified by the pathogen. Defense responses are triggered when the R protein detects an attempt to attack its guardee, which might not necessarily involve direct interaction between the $\mathrm{R}$ and Avr proteins. Efforts to transfer $R$ genes from model species to crops, or between distantly related crop species, could be hampered by a phenomenon termed "restricted taxonomic functionality (RTF)" [19]. RTF might be caused by variance or absence of an appropriate guardee, rather than the inability of the $\mathrm{R}$ protein to recognize pathogen effectors in a different host [27]. If this is the case, $R B M 1$ alone may not confer full resistance due to the absence of a specific guardee in $N$. tabacum. Therefore, transfer of guard-guardee pairs might extend the range of $R$ gene functionality and overcome the RTF limitation.

The production of antimicrobial pathogenesis-related (PR) proteins was first identified to function in defense against tobacco mosaic virus (TMV) infection of tobacco plants [28]. PR proteins include hydrolytic enzymes and defensins, which destroy pathogenic microbes through the hydrolysis of pathogen cell walls and disruption of the pathogen membrane, respectively. Genetic studies in Arabidopsis thaliana 
have shown that distinct sets of PR proteins are induced in response to different pathogens. Dependent on salicylic acid (SA) signaling, PRla, PR2 (a $\beta$-1,3-glucanase), and PR5 (thaumatin) are responsive to biotrophic pathogens, while $P R 3$ (a chitinase), $P R 4$ (a chitinase), and PR12 (a defensin) are induced by necrotrophic pathogens via the jasmonic acid (JA)-dependent signaling pathway [29]. Increased tolerance to the biotroph $P$. tabacina was demonstrated in transgenic tobacco over-expressing PRla or $\beta$-1,3-glucanase [30,31]. In our study, quantitative analysis of $P R 1$ and $P R 4$ suggest that both genes are activated in TKF 4321 (Figure 2), indicating that a complicated reaction combining defense responses against both biotrophic and necrotrophic pathogens is induced in the host in response to $P$. tabacina infection. The antagonism between the SA and JA signaling pathways in the plant immune network has been well documented [32-34]. Therefore, one question raised here is how these two pathways are conciliated to a synergic mechanisms conferring resistance to blue mold in tobacco.

Production of reactive oxygen species, as well as inducible expression of PRla, are markers of SA accumulation. Elevated $\mathrm{H}_{2} \mathrm{O}_{2}$ levels and PRla gene expression in TKF 4321 (Figure 3) induced by $P$. tabacina infection indicate that SA-dependent signaling pathways are involved in triggering defense reactions. In the natural environment, plants can be infected simultaneously or sequentially by various pathogens with diverse strategies and lifestyles. The antagonistic interaction between the SA and JA signaling pathways has been proposed to be an efficient mechanism to prioritize one over the other, depending on the type of the invading pest or pathogen. We hypothesize that the exceptional defense signaling in blue mold resistance may result from the rapid rate of colonization and the short life cycle of $P$. tabacina because sporangiospores can be produced in as few as five days after the initial infection (Figure 1). If the HR-induced necrosis is unable to keep pace with hyphal development in leaf tissues, the lesions that result from cell death will expand to cover large areas of the leaf, which is also harmful for tobacco growth. In addition, if the initial infection is not controlled in time, the subsequent production and dispersal of infective sporangia can initiate a disease epidemic. Therefore, both the HR reaction, which is specific to biotrophs, and also the defense response against necrotrophs are activated to restrict the rapid colonization of $P$. tabacina. In this scenario, SA signaling-mediated systemic acquired resistance (SAR) protects uninfected parts from further damage, and the JA-dependent immune response suppress hyphal development in living tissues outside the necrotic infection sites. A previous observation of the SA-JA synergistic interactions can shed more light on our understanding of blue mold resistance [35]. A synergistic effect of the JA- and SA-dependent signaling pathways was observed when Arabidopsis was treated with low concentrations of JA and SA; however, under higher concentrations the effects were antagonistic, demonstrating that the outcome of the SA-JA interaction is dependent upon the relative abundance of each hormone [35]. We assume that the delayed perception of $P$. tabacina infection fails to induce high concentrations of JA or SA; accordingly, a synergistic SA-JA interaction was achieved. Convincing evidence for involvement of SA, JA, and PR4 in resistance to blue mold in tobacco is lacking at present, and will almost certainly require a study using transgenic plants.

It has been reported that some accessions of $N$. langsdorffii, a wild Brazilian tobacco relative, express resistance to $P$. tabacina infection by developing HR-induced necrotic lesions that eliminate subsequent pathogen colonization and sporulation. This resistance is conferred by a single, dominant gene named NIRPT [36,37]. Incompatible interactions with P. tabacina have also been identified in N. obtusifolia genotypes expressing HR caused by a single, partially dominant gene known as Rptl [38]. Although several sources of genetic resistance to $P$. tabacina are available, we cannot predict whether the genetic 
effects mediated by these genes will be intact after transfer to tobacco by hybridization. To better exploit blue mold resistance in exotic relatives of tobacco, we need to characterize the mechanism(s) underlying the weakened immunity in tobacco. As for the incomplete $R B M 1$-mediated resistance expressed in tobacco, our current hypotheses involve impaired effects caused by tobacco modification genes and the unsuccessful transfer of a complete multi-genic system that is responsible for resistance from $N$. debneyi. Gene cloning and functional analysis of $R B M 1$ will help explain why the complete resistance to $P$. tabacina infection seen in wild species is reduced in tobacco. Therefore, the genetic mapping of $R B M 1$ described herein will provide a foundation for molecular cloning of this gene and for engineering of RBMI-mediated resistance.

\section{Experimental Section}

\subsection{The Mapping Population}

The $\mathrm{F}_{2}$ mapping population was derived from a cross between the two burley tobacco genotypes TKF 4321 (resistant) and TKF 2002 (susceptible). Blue mold resistance in TKF 4321 was inherited from NC-BMR 90, and the ultimate donor of resistance is believed to be $N$. debneyi [9]. Seedlings of the two parental lines, the $\mathrm{F}_{1}$, and the segregating $\mathrm{F}_{2}$ population were grown in a growth chamber under a $16 \mathrm{~h}$ light, $23{ }^{\circ} \mathrm{C} / 8 \mathrm{~h}$ dark, $20^{\circ} \mathrm{C}$ regime for about six weeks before inoculation with the pathogen.

\subsection{P. tabacina Culture and Inoculation}

P. tabacina isolate KY 79 was used for inoculation in the present study [39]. The isolate was continuously maintained and propagated on eight- to 12 -week-old plants of $N$. tabacum cv. KY 14 as previously described [37]. The infective sporangia were collected and washed three times by filtration with sterile deionized water, with the final concentration being adjusted to $1 \times 10^{5}$ spores per $\mathrm{ml}$. Tobacco leaves were inoculated by spraying with the spore suspension, and the inoculated plants were placed in large pre-moistened plastic tubs overnight. Plant reactions to blue mold infection were scored at 7 dpi (days post inoculation) and double-checked at $12 \mathrm{dpi}$. To investigate whether the hypersensitive response (HR) was involved in RBMI-mediated resistance to $P$. tabacina, we used inoculated tobacco leaves manually. The undersides of the leaves were nicked with a syringe needle and the inoculum was forced into the apoplast using a 1-ml disposable syringe with no needle. The inoculated plants were scored four days after injection. Incompatible (hypersensitive) responses were observed as areas of brown sunken tissue at the infiltration sites.

\subsection{Microscopic Analysis of Inoculated Leaves}

Cytological analyses were conducted to monitor the progress of tissue colonization by P. tabacina. Inoculated leaves were cleared and fixed in Farmer's fluid (acetic acid/ethanol/chloroform = 1:6:3 v/v), and pathogen structures were detected by trypan blue staining [37,40]. Trypan blue was dissolved in a 1:2 mixture of lactophenol/ethanol with a final concentration of $0.03 \%(w / v)$. Lactophenol was made by adding $10 \mathrm{~g}$ of phenol to a mixture of $10 \mathrm{~mL}$ of lactic acid, $10 \mathrm{~mL}$ of glycerol, and $10 \mathrm{~mL}$ of distilled water. Fixed leaves were stained at $100{ }^{\circ} \mathrm{C}$ in a water bath for $2 \mathrm{~min}$, followed by de-staining in chloral 
hydrate solution $(2.5 \mathrm{~g} / \mathrm{mL})$ at room temperature with gentle shaking prior to being examined with a light microscope.

\subsection{Quantification of Endogenous Reactive Oxygen Species (ROS) in Tobacco Leaves}

The $\mathrm{H}_{2} \mathrm{O}_{2}$ concentration was measured according to Chanda et al. [41]. Small leaf tissue samples $(\sim 100 \mathrm{mg})$ were homogenized in $500 \mu \mathrm{L}$ of $40 \mathrm{mM}$ Tris- $\mathrm{HCl}(\mathrm{pH} 7.5)$ and centrifuged $(10,000 \mathrm{rpm})$ at $4{ }^{\circ} \mathrm{C}$ for $10 \mathrm{~min}$. A $20 \mu \mathrm{L}$ aliquot of the supernatant solution was added to $80 \mu \mathrm{L}$ of a mixture consisting of $77 \mu \mathrm{L} 40 \mathrm{mM}$ Tris- $\mathrm{HCl}(\mathrm{pH} 7.5), 2 \mu \mathrm{L} 1 \mathrm{mM}$ DCFDA (2', 7'-dichlorofluorescin diacetate; Sigma-Aldrich, St. Louis, MO, USA) and $1 \mu \mathrm{L} 20 \mathrm{mg} / \mathrm{mL}$ HRP (horse radish peroxidase; Sigma). The samples were incubated for one hour in the dark, and $\mathrm{H}_{2} \mathrm{O}_{2}$ levels were measured using a spectrophotometer. The concentration of $\mathrm{H}_{2} \mathrm{O}_{2}$ was determined as $\mathrm{mmol} / \mathrm{mg}$ protein by extrapolating from the standard $\mathrm{H}_{2} \mathrm{O}_{2}$ curve. Total protein was measured using the Bradford Assay which contained $10 \mu \mathrm{L}$ sample supernatant, $90 \mu \mathrm{L}$ dd $\mathrm{H}_{2} \mathrm{O}$ and $900 \mu \mathrm{L}$ Coomassie Protein Assay Reagent (Thermo Scientific, Waltham, MA, USA). $\mathrm{H}_{2} \mathrm{O}_{2}$ levels were measured from four independent samples collected from both parental lines at each time point.

\subsection{Real-Time PCR}

Total RNA was extracted with the RNeasy Plant Mini Kit (Qiagen, Valencia, CA, USA) from tobacco leaves collected from TKF 2002 and TKF 4321 plants that had been previously inoculated with $P$. tabacina at $0,6,12,24,48,72,96$, and $120 \mathrm{hpi}$ (hours post inoculation). Three biological replicates were performed for each variety at each time point. First-strand cDNA was synthesized using M-MLV Reverse Transcriptase (Invitrogen) according to the manufacturer's instructions. Fluorescence PCR amplifications were performed in triplicate using the StepOne real-time PCR system (Applied Biosystems, Grand Island, NY, USA). A $2 \mu \mathrm{L}$ aliquot of each first strand cDNA equivalent of $20 \mathrm{ng}$ of total RNA was amplified using primer pairs specific to the tobacco actin, $H S R$, and $P R$ genes in a $20 \mu \mathrm{L}$ reaction containing $2 \mu \mathrm{L}$ of each primer $(2.5 \mu \mathrm{M}), 8.8 \mu \mathrm{L}$ of water, and $10 \mu \mathrm{L}$ of iTaq SYBR Green Supermix with ROX (Bio-Rad, Hercules, CA, USA). The names and sequences of the primers used for real-time analysis in this study are: Actin-Forward, 5'-AGGGTTGCTGGAGATGATG-3', Actin-Reverse, 5'-CGGGTTAAGAGGTGCTTCAG-3'; PR-1aF, 5'-GGATGCCCATAACACAGCTC3', PR-1aR, 5'-GCTAGGTTTTCGCCGTATTG-3'; PR-4rtpF, 5'-GGCCAAGATTCCTGTGGTAGAT3', PR-4rtpR, 5'-CACTGTTGTTTGAGTTCCTGTTCCT-3'. Amplification conditions were: denaturation at $95{ }^{\circ} \mathrm{C}$ for $2 \mathrm{~min}$, followed by 35 cycles of $95{ }^{\circ} \mathrm{C}$ for $30 \mathrm{~s}, 51^{\circ} \mathrm{C}$ for $30 \mathrm{~s}$, and $72{ }^{\circ} \mathrm{C}$ for 30 $\mathrm{s}$, with a final extension at $72{ }^{\circ} \mathrm{C}$ for $5 \mathrm{~min}$.

\subsection{Genetic Mapping and Marker Design}

We initially mapped SSR (simple sequence repeat) markers with known genetic positions to localize the approximate position of $R B M 1$, based on the high-density genetic linkage map of tobacco [15]. Additional markers were then developed from tobacco genome sequence contigs that harbor mapped SSR markers [1]. Only susceptible plants from the initial scoring and resistant plants from the second scoring were used for genetic mapping. The initial mapping population consisted of 93 
$\mathrm{F}_{2}$ plants. The size of the mapping population was increased to include 415 susceptible individuals for fine mapping. The genetic linkage map was constructed with Mapmaker version 3.0 [42] (Lander et al. 1987). All markers described in this paper are listed in Table 1.

Table 1. Molecular markers described in this study.

\begin{tabular}{ccll}
\hline $\begin{array}{c}\text { Marker } \\
\text { Name }\end{array}$ & $\begin{array}{c}\text { Marker } \\
\text { Type }\end{array}$ & \multicolumn{1}{c}{ Left Primer } & \multicolumn{1}{c}{ Right Primer } \\
\hline PT53422 & SSR & CGCACATACGTACTGAGCATT & GGCTCGAACCCGTAACCTAT \\
PT61472 & SSR & TCCAATACCTTTAATGCATCTCC & GCATGACATGTTGAAGTGGG \\
PT61512Y & SSR & ATCGGACCCAAAGTTTAAGAAACAA & AGGCAAGGATAGGGATAGGAATAGC \\
PT51405 & SSR & AAGTTGGTTATAATCTCGATGCC & AATTCATCTCCAACGCAACTG \\
PT52753 & SSR & TTGGGCCTAGTTTCTACGGA & CAATGCTAACCTGTCACTACCA \\
PT60799 & SSR & GCCGCAGTACTAAAGCTCAGA & TGCACAATCTTCAGGTCAGC \\
PT54257 & SSR & GCAGCACCCAAGTTGCTTA & CCGTCTATTAGCATCAAGGCA \\
SCAR1 & SCAR & CTGAGTTTGGCCGAATAGCAT & CAAACGTCCTAAATGGGGTATAA \\
SCAR2 & SCAR & GTCTACGGCAAGGGGAGATATTA & GTCTACGGCAGCAATCAACATG \\
\hline
\end{tabular}

\section{Conclusions}

In the present study, we characterized the RBMI-mediated resistance to blue mold, a destructive disease in tobacco. Concomitant with elevated $\mathrm{H}_{2} \mathrm{O}_{2}$ levels and PRla gene expression, hypersensitive response (HR) plays an important role in the host defense reactions. Although $R B M 1$ confers completed resistance to $P$. tabacina in the original donor, $N$. debneyi, field experiments showed that $R B M I$ is a semi-dominant gene with incomplete immunity in tobacco. Genetic mapping indicated that this disease resistance gene resides on chromosome 7. Therefore, our work described herein will enable the molecular cloning of this gene and the engineering of $R B M 1$-mediated resistance.

\section{Acknowledgments}

We thank James T. Hall for maintaining the blue mold pathogen and for his help with plant inoculations. We are grateful to the Kentucky Tobacco Research \& Development Center (KTRDC) for providing facilities and growth chamber. This work was supported by British American Tobacco (to Shengming Yang).

\section{Author Contributions}

Dandan Li, David Zaitlin, Robert Miller, and Shengming Yang conceived and designed the experiments; Xia Wu, Dandan Li, and Yinguang Bao performed the experiments; Xia Wu, Dandan Li, Yinguang Bao, Robert Miller, and Shengming Yang analyzed the data; Xia Wu, David Zaitlin, and Shengming Yang wrote the manuscript.

\section{Conflicts of Interest}

The authors declare that they have no conflict of interest. 


\section{References}

1. Sierro, N.; Battey, J.N.; Ouadi, S.; Bakaher, N.; Bovet, L.; Willig, A.; Goepfert, S.; Peitsch, M.C.; Ivanov, N.V. The tobacco genome sequence and its comparison with those of tomato and potato. Nat. Commun. 2014, 5, 3833, doi:10.1038/ncomms4833.

2. Zhang, J.; Zhang, Y.; Du, Y.; Chen, S.; Tang, H. Dynamic metabonomic responses of tobacco (Nicotiana tabacum) plants to salt stress. J. Proteome Res. 2011, 10, 1904-1914.

3. Caplan, J.L.; Mamillapalli, P.; Burch-Smith, T.M.; Czymmek, K.; Dinesh-Kumar, S.P. Chloroplastic protein NRIP1 mediates innate immune receptor recognition of a viral effector. Cell 2008, 132, 449-462.

4. Whitham, S.; Dinesh-Kumar, S.P.; Choi, D.; Hehl, R.; Corr, C.; Baker, B. The product of the tobacco mosaic virus resistance gene $N$ : Similarity to toll and the interleukin-1 receptor. Cell 1994, $78,1101-1115$.

5. Heist, E.P.; Nesmith, W.C.; Schardl, C.L. Interactions of Peronospora tabacina with Roots of Nicotiana spp. in Gnotobiotic Associations. Phytopathology 2002, 92, 400-405.

6. Schiltz, P. Downy mildew of tobacco. In The Downy Mildews; Spencer, D.M., Ed.; Academic Press: London, UK, 1981; pp. 577-599.

7. Rufty, R.C. Genetics of host resistance to tobacco blue mold. In Blue Mold of Tobacco; McKean, W.E., Ed.; American Phytopathological Society: St. Paul, MN, USA, 1989; pp. 141-164.

8. Clayton, E.E. The transfer of blue mold resistance from Nicotiana debneyi. Part III. Development of a blue mold resistant cigar wrapper variety. Tob. Sci. 1967, 11, 107-110.

9. Milla, S.R.; Levin, J.S.; Lewis, R.S.; Rufty, R.C. RAPD and SCAR markers linked to an introgressed gene conditioning resistance to Peronospora tabacina D.B. Adam. in tobacco. Crop Sci. 2005, 45 , 2346-2354.

10. Wark, D.C. Nicotiana species as sources of resistance to blue mold (Peronospora tabacina Adam) for cultivated tobacco. In Proceedings of the 3rd World Tobacco Science Congress, Salisbury, Southern Rhodesia, 18-26 February 1963, Tobacco Research Board: Harare, Zimbabwe, 1963; pp. 252-259.

11. Wark, D.C. Development of flue-cured tobacco cultivars resistant to a common strain of blue mold. Tob. Sci. 1970, 147-150.

12. Rufty, R.C.; Main, C.E. Components of partial resistance to blue mold in six tobacco genotypes under controlled environmental conditions. Phytopathology 1989, 79, 606-609.

13. Wuttke, H.H. Blue mould resistance in tobacco. Aust. Tob. Grow. Bull 1972, 20, 6-10.

14. Julio, E.; Verrier, J.L.; Dorlhac de Borne, F. Development of SCAR markers linked to three disease resistances based on AFLP within Nicotiana tabacum L. Theor. Appl. Genet. 2006, 112, 335-346.

15. Bindler, G.; Plieske, J.; Bakaher, N.; Gunduz, I.; Ivanov, N.; van der Hoeven, R.; Ganal, M.; Donini, P. A high density genetic map of tobacco (Nicotiana tabacum L.) obtained from large scale microsatellite marker development. Theor. Appl. Genet. 2011, 123, 219-230.

16. Pontier, D.; Gan, S.; Amasino, R.M.; Roby, D.; Lam, E. Markers for hypersensitive response and senescence show distinct patterns of expression. Plant Mol. Biol. 1999, 39, 1243-1255.

17. Tudzynski, P.; Heller, J.; Siegmund, U. Reactive oxygen species generation in fungal development and pathogenesis. Curr. Opin. Microbiol. 2012, 15, 653-659. 
18. Hammond-Kosack, K.E.; Tang, S.; Harrison, K.; Jones, J.D. The tomato $C f$-9 disease resistance gene functions in tobacco and potato to confer responsiveness to the fungal avirulence gene product avr 9. Plant Cell 1998, 10, 1251-1266.

19. Tai, T.H.; Dahlbeck, D.; Clark, E.T.; Gajiwala, P.; Pasion, R.; Whalen, M.C.; Stall, R.E.; Staskawicz, B.J. Expression of the Bs2 pepper gene confers resistance to bacterial spot disease in tomato. Proc. Natl. Acad. Sci. USA 1999, 96, 14153-14158.

20. Thilmony, R.L.; Chen, Z.; Bressan, R.A.; Martin, G.B. Expression of the tomato Pto gene in tobacco enhances resistance to Pseudomonas syringae pv tabaci expressing avrPto. Plant Cell 1995, 7, 1529-1536.

21. Whitham, S.; McCormick, S.; Baker, B. The N gene of tobacco confers resistance to tobacco mosaic virus in transgenic tomato. Proc. Natl. Acad. Sci. USA 1996, 93, 8776-8781.

22. Baudouni, E.; Charpenteau, M.; Roby, D.; Marco, Y.; Ranjeva, R.; Ranty, B. Functional expression of a tobacco gene related to the serine hydrolase family-Esterase activity towards short-chain dinitrophenyl acylesters. Eur. J. Biochem. 1997, 248, 700-706.

23. Pontier, D.; Tronchet, M.; Rogowsky, P.; Lam, E.; Roby, D. Activation of hsr203, a plant gene expressed during incompatible plant-pathogen interactions, is correlated with programmed cell death. Mol. Plant Microbe Interact. 1998, 11, 544-555

24. Pontier, D.; Balague, C.; Bezombes-Marion, I.; Tronchet, M.; Deslandes, L. Identification of a novel pathogen-responsive element in the promoter of the tobacco gene HSR203J, a molecular marker of the hypersensitive response. Plant J. 2001, 26, 495-507.

25. Takahashi, Y.; Uehara, Y.; Berberich, T.; Ito, A.; Saitoh, H.; Miyazaki, A.; Terauchi, R.; Kusano, T. A subset of hypersensitive response marker genes, including HSR203J, is the downstream target of a spermine signal transduction pathway in tobacco. Plant J. 2004, 40, 586-595.

26. Van der Biezen, E.A.; Jones, J.D. Plant disease-resistance proteins and the gene-for-gene concept. Trends Biochem. Sci. 1998, 23, 454-456.

27. McDowell, J.M.; Woffenden, B.J. Plant disease resistance genes: Recent insights and potential applications. Trends Biotechnol. 2003, 21, 178-183.

28. Van Loon, L.C.; van Kammen, A. Polyacrylamide disc electrophoresis of the soluble leaf proteins from Nicotiana tabacum var. "Samsun" and "Samsun NN". II. Changes in protein constitution after infection with tobacco mosaic virus. Virology 1970, 40, 190-211.

29. Thomma, B.P.; Eggermont, K.; Penninckx, I.A.; Mauch-Mani, B.; Vogelsang, R.; Cammue, B.P.; Broekaert, W.F. Separate jasmonate-dependent and salicylate-dependent defense-response pathways in Arabidopsis are essential for resistance to distinct microbial pathogens. Proc. Natl. Acad. Sci. USA 1998, 95, 15107-15111.

30. Alexander, D.; Goodman, R.M.; Gut-Rella, M.; Glascock, C.; Weymann, K.; Friedrich, L.; Maddox, D.; Ahl-Goy, P.; Luntz, T.; Ward, E.; et al. Increased tolerance to two oomycete pathogens in transgenic tobacco expressing pathogenesis-related protein. Proc. Natl. Acad. Sci. USA 1993, 90, 7327-7331.

31. Lusso, M.; Kuc, J. The effect of sense and antisense expression of the PR-N gene for $\beta$-1,3-glucanase on disease resistance of tobacco to fungi and viruses. Physiol. Mol. Plant Pathol. 1996, 49, 267-283. 
32. Gupta, V.; Willits, M.G.; Glazebrook, J. Arabidopsis thaliana EDS4 contributes to salicylic acid (SA)-dependent expression of defense responses: Evidence for inhibition of jasmonic acidsignaling by SA. Mol. Plant Microbe Interact. 2000, 13, 503-511.

33. Koornneef, A.; Leon-Reyes, A.; Ritsema, T.; Verhage, A.; Den Otter, F.C.; van Loon, L.C.; Pieterse, C.M. Kinetics of salicylate-mediated suppression of jasmonate signaling reveal a role for redox modulation. Plant Physiol. 2008, 147, 1358-1368.

34. Spoel, S.H.; Koornneef, A.; Claessens, S.M.C.; Korzelius, J.P.; van Pelt, J.A.; Dong, X.; Pieterse, C.M. NPR1 modulates cross-talk between salicylate- and jasmonate-dependent defense pathways through a novel function in the cytosol. Plant Cell 2003, 15, 760-770.

35. Mur, L.A.; Kenton, P.; Atzorn, R.; Miersch, O.; Wasternack, C. The outcomes of concentration-specific interactions between salicylate and jasmonate signaling include synergy, antagonism, and oxidative stress leading to cell death. Plant Physiol. 2006, 140, 249-262.

36. Zhang, S.; Gao, M.; Zaitlin, D. Molecular linkage mapping and marker-trait associations with NIRPT, a downy mildew resistance gene in Nicotiana langsdorffii. Front. Plant Sci. 2012, 3, 185, doi:10.3389/fpls.2012.00185.

37. Zhang, S.; Zaitlin, D. Genetic resistance to Peronospora tabacina in Nicotiana langsdorffii, a South American wild tobacco. Phytopathology 2008, 98,519-528.

38. Heist, E.P.; Zaitlin, D.; Funnell, D.L.; Nesmith, W.C.; Schardl, C.L. Necrotic lesion resistance induced by Peronospora tabacina on Leaves of Nicotiana obtusifolia. Phytopathology 2004, 94, 1178-1188.

39. Reuveni, M.; Nesmith, W.C.; Siegel, M.R. Symptom development and disease severity in Nicotiana tabacum and N. repanda caused by Peronospora tabacina. Plant Dis. 1986, 70, 727-729.

40. Keogh, R.C.; Deverall, B.J.; McLeod, S. Comparison of histological and physiological responses to Phakopsora pachyrhizi in resistant and susceptible soybean. Trans. Br. Mycol. Soc. 1980, 74, 329-333.

41. Chanda, B.; Venugopal, S.C.; Kulshrestha, S.; Navarre, D.A.; Downie, B.; Vaillancourt, L.; Kachroo, A.; Kachroo, P. Glycerol-3-phosphate levels are associated with basal resistance to the hemibiotrophic fungus Colletotrichum higginsianum in Arabidopsis. Plant Physiol. 2008, 147, 2017-2029.

42. Lander, E.S.; Green, P.; Abrahamson, J.; Barlow, A.; Daly, M.J.; Lincoln, S.E.; Newburg, L. MAPMAKER: An interactive computer package for constructing primary genetic maps of experimental and natural populations. Genomics 1987, 1, 174-181.

(C) 2015 by the authors; licensee MDPI, Basel, Switzerland. This article is an open access article distributed under the terms and conditions of the Creative Commons Attribution license (http://creativecommons.org/licenses/by/4.0/). 